\title{
Confirmación del diagnóstico microbiológico en casos de absceso del músculo iliopsoas
}

\author{
V. Navarro López \\ Unidad de Enfermedades Infecciosas. Servicio de Medicina Interna Hospital Vega Baja de Orihuela. Alicante.
}

Actas Urol Esp 2006; 30(2): 232-233

Sr. Director:

En relación con el artículo publicado en su revista Actas Urol Esp 2005; 29 (7): 704-707 "Absceso del psoas brucelósico bilateral: presentación de un caso y revisión de la literatura" por Romero Otero $\mathrm{V}$ et al. ${ }^{1}$, creo conveniente puntualizar algunos aspectos del interesante caso de absceso del músculo iliopsoas (AIP) bilateral que presentan. En primer lugar el relacionado con el diagnóstico microbiológico de la infección brucelar y en segundo lugar sobre el tratamiento antibiótico empírico recomendado en casos de AIP.

Es cierto como dicen los autores que el diagnóstico microbiológico de la infección por Brucella $s p$ se realiza tanto por cultivo como por métodos serológicos. Las pruebas serológicas más utilizadas son el Rosa de bengala, que suele usarse como método de screening debido a su alta sensibilidad (cercana al $100 \%$ de los casos de infección brucelar confirmada), pero que no sirve como método de diagnóstico debido a que tiene baja especificidad sobre todo en zonas endémicas donde el número de pacientes con positividad del rosa de bengala sin haber desarrollado la enfermedad brucelar es elevado $^{2}$. Además en casos de infección antigua esta prueba suele ser positiva durante largos periodos de tiempo, en ocasiones de por vida ${ }^{3}$. Por contra, las aglutinaciones antibrucella con títulos mayores o iguales de $1 / 160$ o bien cuando se confirma una seroconversión con incremento de los títulos de al menos 4 veces el valor basal se aceptan como diagnóstico probable de infección bruce$\operatorname{lar}^{2-4}$. El caso presentado no cumple ninguno de los criterios aceptados para el diagnóstico microbiológico al tener cultivos negativos y aglutinaciones a títulos bajos. Por lo expuesto, el caso clínico que describen los autores, con absoluta normalidad de los parámetros hematimétricos y bioquími- cos y con unas aglutinaciones cuantificadas en una sola ocasión de 1/20 no puede definirse como AIP de origen brucelar, pues ni siquiera cumple criterios de brucelosis probable.

Ante la descripción realizada nos encontramos con un caso de AIP con espondilodiscitis y en esta situación el diagnóstico microbiológico más probable es la infección por Gram positivos, principalmente Estafilococos sp o Estreptococos $s p$ y con menor frecuencia por Gram negativos y anaerobios entéricos. También ha de tenerse en cuenta la posibilidad de espondilodiscitis tuberculosa que en los últimos años ha cobrado mayor relevancia sobre todo en relación con la mayor prevalencia de la infección por el $\mathrm{VIH}^{5}$. El hecho de que todos los hemocultivos y cultivos del absceso una vez drenado sean negativos no es excepcional y se encuentra descrito en las principales series de casos de AIP en porcentajes cercanos al $20 \%$. En nuestra experiencia recogida en una serie amplia de AIP y comunicada previamente por el Grupo de Trabajo de Enfermedades Infecciosas de la Sociedad Española de Medicina Interna esto ocurre en un $17,7 \%$ de ellos ${ }^{6}$.

La mala evolución que presenta el caso descrito por los autores y que finalmente provoca que tenga que ser drenado quirúrgicamente podría deberse en parte a una inadecuada cobertura antibiótica inicial de los gérmenes más prevalentes en AIP secundarios a espondilodiscitis. Posiblemente con el uso de la doxiciclina, la estreptomicina y el ciprofloxacino se logró controlar en parte la infección sin llegar a su curación, de ahí la posterior recidiva del cuadro con progresión del AIP.

Como conclusión en un porcentaje no despreciable de casos de AIP el diagnóstico microbiológico es imposible de realizar y por ello es impor- 
tante el diagnosticar el probable origen de la infección del músculo psoas para emplear un adecuado tratamiento antibiótico empírico. Cuando el AIP sea secundario a una espondilodiscitis como es el caso, el tratamiento empírico debería contemplar el uso de un beta-lactámico con actividad frente a las beta-lactamasas o una cefalosporina de $2^{\mathrm{a}} / 3^{\mathrm{a}}$ generación, siendo opcional el uso inicial de un aminoglucósido. En los casos de mala evolución habría que plantear la posibilidad de infección tuberculosa. Sólo en contadas excepciones será necesario el uso empírico de un tratamiento para cubrir la infección brucelar pues en los pocos casos en que se ha diagnosticado el AIP por Brucella sp la epidemiología ha hecho sospechar el diagnóstico que se ha confirmado mediante cultivos y/o serología a títulos mayores o iguales a 1/160 de aglutinaciones antibrucela en todos los casos publicados hasta el momento ${ }^{6-11}$.

\section{REFERENCIAS}

1. Romero Otero J, Martínez Silva M, Pamplona Casamayor C, Capitán Manjón C, Piedra J, Leiva O. Absceso de psoas brucelósico bilateral: presentación de un caso y revisión de la literatura. Act Urol Esp. 2005;29(7):704-707.

2. Colmenero JD, Reguera JM, Martos F, Sánchez de Mora, Delgado M, Causse M, et al. Complications associated with Brucella melitensis infection: A study of 530 cases. Medicine. (Baltimore) 1996;75:195-211.

3. Young EJ. Brucella Species. En: Mandell GL, Bennett JE, Dolin R, editors. En: Principles and Practice of Infeccious Diseases. 5th ed. New York: Churchill Livigstone, 2000; 2386-2393.

4. Solera J, Lozano E, Martínez-Alfaro E, Espinosa A, Castillejos ML, Abad L. Brucellar espondilitis: Review of 35 cases and literature survey. Clin Infect Dis 1999;29:14401449 .

5. Navarro López V, López García F, González Escoda E, Gregori Colomé J, Muñoz Pérez A.. Psoas abscess in patients infected with the human immunodeficiency virus Eur J Clin Microbiol Infect Dis. 2004;23(8):661-663.

6. Navarro López V, Amorós F, Pacheco I, Gregori J, Ramos JM, Serrano R et al. Psoas muscle abscess. Description of a series of 121 cases. Oral presentation in 27th Worl Congress of Internal Medicine. Granada. Spain, September-October 2004 .
7. Colmenero JD, Fernández-Nebro A, Reguera JM, Villanueva F. Psoas abscess secondary to brucellosis. J Infect 1991;22(1):107-9.2.

8. Jayakumar RV, Al-Aska AK, Subesinghe N,Whright SG. Unusual presentation of culture positive brucellosis. Postgrad Med J 1988;64 (748):118-120.

9. Metola Sacristán L, Acha Arrieta A, García de Lucas MD, Casas Fernández de Tejerían JM. Espondilitis y absceso bilateral de psoas por Brucella. An Med Intern 1995;12(9): 465-456.

10. Fabregas MD, Serrano R, Pons J, Aznar R. Brucella y absceso de psoas bilateral. Enferm Infecc Microbiol Clin 1991;9:446-447.

11. Baena JM, Alegret F, De Otero J, Pigrau C. Absceso de psoas secundario a sacroileítis. Med Clin (Barc) 1995; 104: 359.

Fdo.: Dr. V. Navarro López

\section{RESPUESTA A LA CARTA DEL DR. NAVARRO}

\section{Sr. Director:}

En relación a la carta al Director "Confirmación del diagnóstico microbiológico en casos de abscesos del músculo iliopsoas" aclarar que: el resultado del estudio serológico que figura en nuestra nota clínica, no es el del diagnóstico, sino el que presentaba el enfermo cuando fue remitido a nuestro centro para drenaje del absceso de psoas bilateral. En ese momento llevaba 6 meses de tratamiento antibiótico y un drenaje transcutáneo de absceso de psoas.

En el momento del diagnóstico el enfermo presentaba: antecedente de riesgo, clinica compatible y un estudio serológico: Rosa de Bengala positiva y seroaglutinación para Brucella positiva 1/640. Fue entonces cuando se diagnosticó de brucelosis aguda y se inició tratamiento en consecuencia.

Fdo: J. Romero Otero 